\title{
The deaf and the classroom design: a contribuition of the built environmental ergonomics for the acessibility
}

\author{
Laura Bezerra Martins $^{\mathrm{a}: \text {; }}$, and Denise Maria Simões Freire Gaudiot ${ }^{\mathrm{b}}$ \\ ${ }^{a}$ Federal University of Pernambuco, Post Graduate Program of Design, Av. Prof. Moraes Rego, 1235 - Cidade \\ Universitária, Recife, PE. Brazil. \\ ${ }^{\mathrm{b}}$ Federal University of Pernambuco, Post Graduate Program of Design, Av. Prof. Moraes Rego, 1235 - Cidade \\ Universitária, Recife, PE. Brazil.
}

\begin{abstract}
In any concept of school design, classroom occupies the central place. Dimensions, lighting, the equipment needed, ventilation are old questions already answered, even in form of laws and standards adopted. However, the best use of available materials and physical conditions of comfort is not sufficient for a classroom design guaranteed success. The classroom should provide deaf students elements to facilitate the learning process, eliminating as much as possible the obstacles created by lack of hearing and allowing them to have the same access to learning as a listener student. As users of a school building, teachers, students, parents and staff are the best evaluators of the physical environment of schools. The environmental comfort is a largest ally of pedagogy. The learning comes from the perception and the concentration of students in the classroom. The purpose of this study is to detect the role of direct perception (physical) and indirect (intangible) elements that informs and have symbolic value, and propose layouts for accessible classrooms to deaf students. The ergonomics of the built environment evaluation methods could use the participatory design method tools as basis to assessing how users perceive and use the school environment.
\end{abstract}

Keywords: Inclusion, education, design participative, layout

\section{Introduction}

Deafness is a disability that is not seen, but is with eyes that the deaf can hear [1]. From there it is necessary to study cognition and perception of deaf students, as well as pedagogical practices and new technologies, which serves as guide to a classroom design that offers the ergonomic standards acceptable to all students, deaf or not. The teachers seek to know how students learn in order to improve training facilities and to devise appropriate teaching techniques to learning [2]. Ergonomics provides tools to monitor the dimension of the teaching-learning situations. Within a classroom the prescribed work for teachers is the number of teaching hours and teaching content, and for the students, learning this content during these hours. The real work will find material conditions not suitable for carrying out the task as: heat, poor lighting, noise, lack of teaching equipment and electronics, among other factors, detrimental to the smooth progress of the job. The students, in the other hand, come with different levels of education, experience and cultural backgrounds. Consequently, the prescribed procedures are not adaptable to the objectives prescribed as well as inadequate. In the case of the classroom one of the most important factors to be analyzed is the physical environment ergonomics. The school environment has direct influence in the behavior of its users [3]. The role of ergonomics is to note what causes the failure in the way information transmission happens between individuals.

\footnotetext{
$\$$ Corresponding authors: laurabm@folha.rec.br, denise.gaudiot@terra.com.br
} 


\section{Parameters of the built environment ergonomics}

The ergonomics acts on the object of study, determining the necessary prerequisites for the suitability of the environment to the users, as well as ensuring its global activities [4].

For a long time prevailed the idea that the ergonomics aimed to correct situations that are malfunctioning. Its purpose should not be limited to repair work problems, but to be present since the design of the built environment, thus avoiding future problems.

The environments design should be done not only in terms of furniture and equipments, but, mainly, based on users and their activities, educational or not, to be developed in that place.

In the case of a school environment, the analysis of activities developed, teaching-learning, is the basis for the definitions of scale, environmental comfort, layout, displacements, safety, materials, and information exchange.

Moreover, it is also necessary to analyze the limitations in which the task runs. Thus it is necessary to obtain data that shape the context in which ergonomic intervention can be performed, with their constraints and limits.

From the viewpoint of the design of the built environment, the professional should develop a project based on the principles of accessibility. The project should have a global reasoning, starting from the exterior and take into account all the movements likely to be made by its users.

Among the deaf the hearing sense has two types of perception: the environment and the sound communication codes, which are responsible for the chain of "real movement".

For his communication needs, a deaf person, first, refers to visual information and then ask for help from another person. So it is essential to dispose of visual communication in and out the used environments. Considering these, it is possible to mention several details in the classroom design that serves to facilitate and improve the quality of life for deaf users. Among them are:

\section{Sunlight and artificial lighting}

Glare, weak lighting and reflections can provide poor vision of the teacher and the subjects in the black-board damaging the students learning process, deaf or not. The natural light is preferable and should be provided in a evenly way, without direct incidence of sunlight. When using artificial lightings, anti-glare devices should be present.

\section{Acoustics}

Deaf student can be very noisy without notice and can use the reverberation as alert and communication. It is therefore important the choice of coating materials that do not cause too much sound absorption and harm audibility within the environment. In addition, one should avoid concave reflective surfaces that concentrate or focus sound energy and cause multiple echoes, as well as hard surfaces, polished and parallel, leading to the phenomenon of multiple reflections.

\section{Accessibility}

A suitable environment is a basic need of the deaf.

The degree of deafness in one person is just one small aspect of his shortcomings and do not necessarily determine the best solution for accessibility or accommodation in the classroom. For some, the ability to adjust the volume of their phones can be enough. For others, the presence of interpreters is essential, while for still others, the ideal would be to have access to the face of the teacher during class. In common there is the visual ability relevant to them, which serves as the instrument of perception and learning.

According to Sahmi [5] from the disabled viewpoint, the definition of accessibility goes through a chain of actual displacement (get oriented, to locate, to access, to enter, to participate and to exit) that depends on the needs of each one. Seen from this point, the logic of the shift is understandable to all and it should not be associated only with "wheelchair" solutions with limited access to places and services. For a deaf person it is easier to move across the city then to get inside a built without the proper intercom entrance device.

\section{Visualization and detection}

In a classroom it is necessary to be in constant communication within and outside the room. These communications can be made through glass display at the doors to prevent the clash between people (deaf do not hear a person on the other side of the door) inside and outside the classroom.

The use of mirrors in the corners of the walls helps the view of who comes in the opposite direction in a corridor, or within the classroom, allowing students to communicate with the room and with the others.

The size of the board is also relevant to the student because depending on where they are seated they 
may lose much of what is written. Besides deaf student requires more time to write and watch the classes. Moreover, teachers complain about the lack of space on the board for more and better visual display of the topics discussed.

\section{Warning Signs}

A major difficulty to a teacher is to draw attention of the deaf student in the classroom. It is necessary that the entire alert or communication sound system also exists in the form of light (visual) signals, more easily perceived, including to signal the end of class. The ringing of a bell, the sound of the intercom or the cry of a person's alert sounds are easily overlooked by the deaf.

It is advisable the use of a switch to turn on and off the signals. Ideally, this signals switch should be placed close to the teacher's desk avoiding unnecessary walking.

\section{Layout of the classroom}

By layout we understand a display of elements based on the better use of its functions and relations. The classroom layout should consider the flow of its users, in performing the tasks, to work efficiently and satisfactorily.

The placement of furniture in a classroom, for example, should not be by chance. The distribution provides security, because human beings need accuracy, regularity, standardization and rationalization. Such items are carried out by mechanical devices and gears of the machine-like organizations or persons.

The school environment should be built as a place in such a way that does not restrict the diversity of uses or adaptation to different circumstances. It is important to give freedom to the teacher in the process of configuration spaces. The classroom is a dynamic space. It should be an enabling environment for different groups and different pedagogies.

Being a "visual" individual, a deaf student may not be able to learn in a traditional layout of classrooms where the benches are lined and the teachers are in front with the board. If the deaf student is placed behind the front row, can have his the vision blocked by the students in front of him , and if placed in front will not see what is happening in the rest of the room, losing the discussions between the others students and the teacher. Another student question of may go unnoticed to a deaf student, as well as an enlightening discussion of an important subject.

The positioning of the interpreter is also fundamental to the layout of the classroom since it is the point of contact between the deaf student and teacher. He must see and be seen by both students and teachers.

According to Renard [6] the deaf student should see the teacher and other students, so it is more advisable to place it in the second row where he can see the reaction of colleagues sitting in front. In addition, the student may feel discriminated against by being in the front row.

The format of the arrangement of classes in a circle or $U$ (when class is expository and is necessary to use the framework) facilitates the exchange with the teacher, who is almost equidistant from students all the time, and interact much more efficient than a classroom with conventional layout. But it is worth noting, that this provision is not advisable in case of classes with a high number of students requiring more than two rows of stalls. In this case it is better to position the benches in different levels.

\section{Methodology}

For this study the analysis of the binomial teaching and learning in a classroom with deaf students, was proposed a hybrid methodology for assessing the built environment. Taking as a base the methodology System-Human-Task-Environment [7] with the support of the participatory methodology [3] in an attempt to fit the desired reality and users questions. Two schools were evaluated with classrooms attended by deaf students in regular educational system inclusive schools and exclusive schools for the deaf.

\subsection{SHTE and Participatory Design}

The SHTE method proposes the ergonomic intervention in five steps. Characterized as the assessment, the first step aimed to know the classroom users, collect and analyze their perceptions about the educational environment, as well as the physical environment where the interactions happen. For this step was applied, as well, tools of participatory methodology as the walkthrough, unsystematic and systematic interviews with the use of questionnaires and a focus group. 


\subsection{Research field}

The first school visited was the SUVAG, a private exclusive school for deaf where $60 \%$ of the teachers are deaf with classrooms from kindergarten to middle school. The second school was Cônego Rochael de Medeiros School, a public school with inclusive classrooms, where no teacher is deaf and only some of them know the sign language.

\subsubsection{Walkthrough SUVAG}

The school is located in an old building with poor maintenance. The classrooms have poor illumination and the furniture is old and not comfortable. The windows are closed and the air conditioning system noisy. The layout is in a semi-circle shape with a media of twelve students per class. Since the lighting is poor, is difficult to read and see the screen. Sometimes one student cannot see when another is asking the teacher and loses his attention. The teacher doesn't have a way to call all the students for attention. When the teacher is deaf and explains using the sign language the class moves faster than with an interpreter. The students have problems in call the teacher attention when he is explain something to another student or turned to the screen.

Only unsystematic and systematic interviews were applied in this school.

\subsubsection{Walkthrough Cônego Rochael de Medeiros School}

The school is also located in an old building with a very poor maintenance. The furniture is old, the flooring is cracked and the walls not painted. Most of the classrooms received the afternoon isolation, which reflects in the blackboard blocking the view of the students and disturbing the teachers.

Beyond the interviews a questionnaire was applied to the deaf students with the help of the interpreter and a teacher who was a sign language user. There were quantitative and qualitative questions and was observed that the students had a lot of trouble in answer because of the poor learning levels and lack of information about a classroom environment. It is necessary to note that being a visual person the deaf have trouble with questionnaires without selfexplained images.

Then a semi-structured interview was made with the users (teachers, interpreters and students) questioning them about the classroom environment and their needs. They complained about the glare in the blackboard, the noise at the corridor during the classes, the poor lighting, the heat, the lack of interpreters for each subject, the difficult in call for the students attention, the high number of students per class, the lack of computers, a more visual courseware, the layout where some students can't see others or the teacher, the teachers clothing which sometimes confuses the sign language understanding, among other rich information about the use of a classroom.

\subsection{Diagnosis}

The tools used for the assessment brought to the conclusion that a focus group with visual propositions and comparative models was necessary to a further discussion about their needs.

For the workshop was invited older students, deaf or sign language users, teachers and interpreters, who had a preview experience in the classrooms and more discernment to discuss their needs.

The presentation was a power point with 15 slides, starting with an explanation of the presentation and what were our goals. Then was showed parameters for a regular classroom project as furniture, acoustics, illumination, ventilation, etc based on literature. Some existing bilingual and inclusive classroom was presents as well as explanations about proposals based on the literature. The last slides proposed for discussion, two layouts for an inclusive classroom for deaf based on the existing literature and walkthrough done at the two schools.

During the proposed theoretical references presentation, the audience was questioned and different points of view noted. Some were:

- Most lamps didn't have anti-glare system to avoid shadows and reflections.

- Ceramic flooring has bad acoustics characteristics.

- The external noises prejudiced the hearing.

- The needs of a concave mirror above the blackboard/screen or at the corners to aloud students to see each other and do not miss questions and explanations.

- The need to create a system to allow the teacher to call the students attention.

- The teachers clothing interfere with the understanding of sign language.

- The class ware should be more visual.

- It is necessary to control the sun glare and luminosity.

- Need of higher assistive technology. 
- A system to keep the subjects for longer at the blackboard without interfere with the others students path.

- Better layout and where was the better place to put the deaf student.

- Light/color alarm system.

- How to see the teacher or interpreter during a slide presentation with the lights turn off.

- Kind of furniture to be used for sign language users since sometimes they drop the pen and pencils during the movements.

- Where was the best place for the interpreter at the classroom?

- The layout flexibility depending upon the didactic way of each teacher.

Considering all these comments, was noted that with the use of participatory design tools as systematic or not systematic visits, interview and a focus group, the users participation is really active and positive with relevant suggestions and of great value for this research.

Therefore was confirmed that in a school environment the direct and indirect users (students, teachers, interpreters, employees, etc) are the better resource to collect information about the needs and potentials of a classroom used by deaf students.

\section{Conclusion}

With all the information collect during the research was observed that ergonomics brings together many disciplines to reach a goal. The human parameters with the tasks and the built environment parameters analysis are the basis to the use of an ergonomic methodology and evaluation of the accessibility in a systemic way. The analysis of the triad human-taskenvironment shows that one only works if in harmony with the others [7], and the user is always the process focus.

To reach accessibility in a classroom the methodology also showed that pedagogy is an ally to the built environment during the deaf student learning process and the teacher and interpreter tasks. The teacher and interpreter behavior and position at the class has great influence in the participation of the students [1].

As a result of the built environment evaluation through the first's steps of the method Human-TaskEnvironment and a design participatory tool as a focus group, was proposed some suggestions and two layouts for classrooms attended by deaf students. They are:
- Flooring coats like vinyl or wood to allow reverberation and to help acoustics

- Acoustic ceilings materials as mineral liner.

- Light colors in the walls.

- Maximum noise 40dB

- Access door with a minimum width of 36 inches and with visor to see who is coming or leaving the class. Also made with acoustic material to avoid the corridors noise.

- Color signal system above the blackboard with a switch beside the teacher desk to alert about attention, danger, breaks, end of classes, etc.

- Layout in circle shape, like figure 1 [8] for classes with fewer students and in a steps audience shape for more students. If it is a inclusive classes the deaf student should be in the second line, which allows him to see the reaction of the front students during the questions/answers, or when in front in diagonal, like figure 2 [8] in relation to the class. In either case no obstacle should be between him and the teacher or interpreter and the blackboard.

- The blackboard should be big enough to keep the information enough time to be written by the deaf students.

- Put corner concave mirrors so the students can see and follow his colleagues.

- The furniture like desk and chair separated are recommended because prevents dropping materials during the sign language use.

- Avoid sun glare in the blackboard and class with curtains or brise soleils outside.

- Forecast the use of electronic material for visual explanation of the subjects, as computers, overhead projector screens, etc.

As a result, the proposed layouts are as follow:
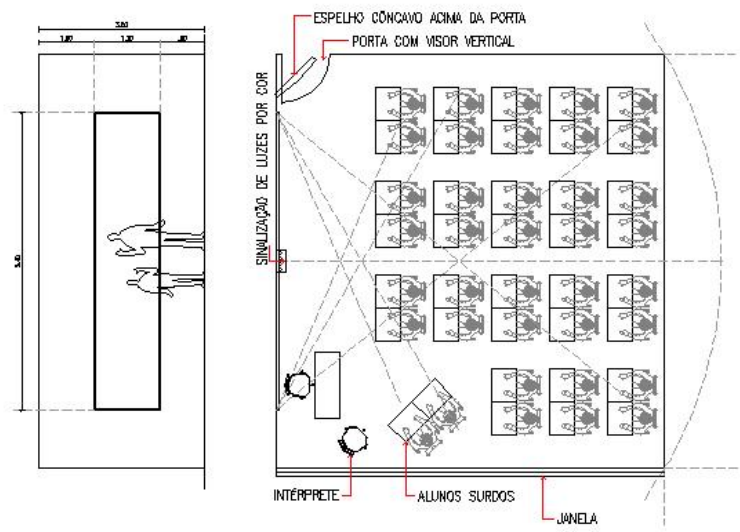

Figure 1. Classroom layout traditional shape. 

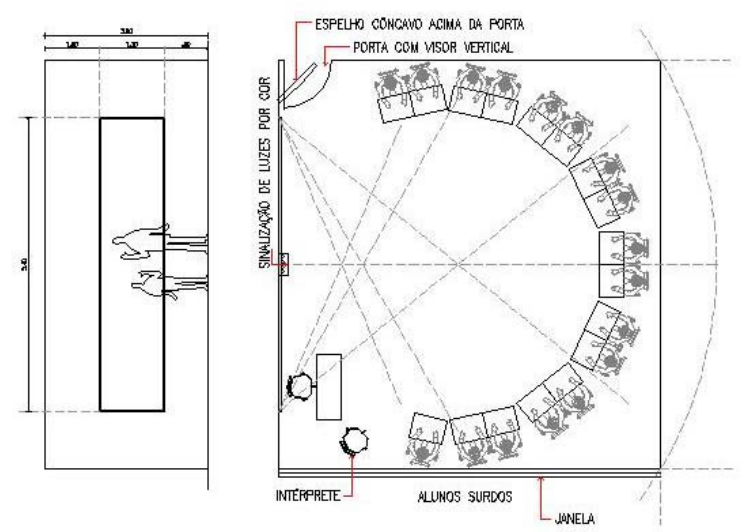

Figure 2. Classroom layout circle shape.

\section{References}

[1] I. de F. De Parny, lês etablissements pour jeunes sourdes em France:Bilan ET prospective, 360f. thesis in architecture. Paris University. 1984.

[2] M. Montmollin, L'Ergonomie. Paris: Ed. La decouverte,2006

[3] H. Sanoff, School programming, design and evaluation: a community/university partnership. In: Revista AmbienteConstruído, Porto Alegre, v.7,n.1, 2007. pp. 7-19

[4] L.B. Martins, Ergonomia e Ambientes físico. course notes of expertise in ergonomics in UFPE, 2007.

[5] N. Sahmi, Concevoir um espace public acessible a tous-Voire, logements collectifs, ERP, IOP, lieux de travail. Accesibilité Handicapés. Paris . Ed. CSTB,2006

[6] M. Renard, Les sourds dans La ville-Surdités et accessibilité.

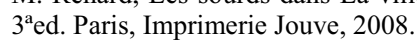

[7] A. Moraes and C. Mont'Alvão, Ergonomia: Conceitos e aplicações. Rio de Janeiro. Ed. iUser,2003.

[8] V. Cortez and M. Braga, Espaços Educativos. Ensino Fundamental. Subsidios para elaboração de projetos e adequação de edificações escolares. Souza José A (Eds). Brasilia: Fundescola/MEC, 2002. 